\title{
TEMPORAL DROUGHT ASSESSMENT USING VARIOUS INDICES OF THE SEYHAN AND CEYHAN BASINS, TURKEY
}

\author{
AlKAN, A.* TOMBUL, M. \\ Department of Civil Engineering, Eskisehir Technical University, Eskisehir 26555, Turkey \\ *Corresponding author \\ e-mail:alialkan18@gmail.com
}

(Received $6^{\text {th }}$ Sep 2021; accepted $23^{\text {rd }}$ Nov 2021)

\begin{abstract}
Drought is a natural phenomenon with various social, environmental, and economic effects. Adverse impacts of drought at a regional and global scale have become more evident with climate change. The Seyhan and Ceyhan basins were chosen as study areas in Turkey. Drought analyses were performed using data from 14 meteorological stations gathered between January 1989 and July 2020 in Standardized Precipitation Index (SPI) and Standardized Precipitation Evapotranspiration Index (SPEI), based on 3-4-6-12 monthly scales. SPI and SPEI are common indices used for drought tracking. The coefficient of determination $\left(\mathrm{R}^{2}\right)$ was found to be 0.954 and used to analyze the regression between the annual SPI and SPEI. According to SPI and SPEI annual analyses results of study area, the driest year was found to be 2014. SPEI determined more arid periods than SPI for the same time scales. Analyses reveal that the dry period in basins has increased in the last decade and the region is facing a risk of drought. Analyses were made to predict and evaluate risks and to help the efficient use of agricultural lands and water resources in the study area during dry periods.
\end{abstract}

Keywords: drought analysis, drought tracking, standardized precipitation index (SPI), standardized precipitation evapotranspiration index (SPEI), precipitation indices

\section{Introduction}

Drought is a climatic event that occurs during periods of insufficient rainfall and has significant negative effects on ecosystems and societies. The phenomenon of drought cannot be explained only as insufficient precipitation in a particular region, precipitation distribution and temperature-related evaporation should also be taken into account (Ahsan, 2020a). The increase in temperatures and the changes in the amount of precipitation shows that drought is intertwined with climate change and should address the phenomenon caused by global warming in recent years (Ahsan, 2020b).

In terms of water resources, drought can be thought of as a quantitative factor arising from the basin response time. In addition to effects on soil moisture, hydrological responses in river and groundwater discharge, factors such as crops and native vegetation affect response times; therefore, analyses should be done on time scales (Lorenzo-Lacruz et al., 2010). Drought types are divided into meteorological, agricultural, hydrological droughts according to time periods. Meteorological, hydrological and agricultural drought are analyzed respectively by considering 1-, 3-, 6and 12- month period. Therefore, it is essential to classify droughts according to specific time scales and to determine and evaluate drought severity accordingly (Homdee et al., 2016).

There are some scientific discussions about the importance of climate parameters in determining the intensity of drought. Parameters such as precipitation, temperature and evapotranspiration affect the drought severity. The importance of precipitation is inevitable for explaining drought variability, but there is no consensus on the necessity of this variable in calculating any drought indices. Nevertheless, neglecting a variant, 
such as evapotranspiration that takes into account climatic water demand is not generally admitted as its impact on drought-related conditions is not understood (Alley, 1984; Chang and Kleopa, 1991). Evapotranspiration rate is mainly affected by evaporation caused by the increase in atmospheric temperature and the effect of heat waves. In most semi-dry and dry zones of the world, potential evapotranspiration is higher than annual rainfall (Beguería et al., 2014). Several studies have shown that other factors that define the magnitude, duration and intensity of precipitation and droughts also should be taken into account. A study comparing different drought indices reveals that indices which use just rainfall data to define climate droughts suggest the best choice (Olukayode Oladipo, 1985).

Droughts are usually classified according to their features as meteorological, agricultural and hydrological (Wilhite and Glantz, 1985). With reduced precipitation, meteorological drought is the most intuitive among them as it is an extreme climatic event that has a more human and social aspect than other droughts. Meteorological droughts are directly related to other droughts types (Zhang and Jia, 2013; Wang et al., 2019). It is difficult to identify and assess the characteristics of drought because of the complexity and severity of the drought. Therefore, in recent years many drought indices have been advanced for monitoring and evaluating drought events.

Most indices and indicators for drought analysis in the literature use rainfall alone or in combination with other meteorological elements as input. Drought indices are variables that show the duration, extent and spatial extent of drought, determined by hydrological and meteorological variables. Standardized Precipitation Index (SPI) and Standardized Precipitation Evapotranspiration Index (SPEI) have multi time scale characteristics that can show types of drought and better express differences in characteristics of drought (Mishra and Singh, 2010). SPI and SPEI are similar, but there are apparent differences in terms of the parameters used when calculating SPI and SPEI. The SPI ensures the calculation of time-related drought in a particular area, considering only precipitation (Zhou et al., 2013; Tao et al., 2014). McKee et al. (1993) developed SPI for monitoring drought, which is an essential tool for determining periodic meteorological droughts using specific time-precipitation data as input parameters. Vicente-Serrano et al. (2010) developed SPEI to evaluate the severity of drought by taking into account evaporation in the environment in which the plant is located. SPEI is counted basis on the cumulative difference between Precipitation $(P)$ and Potential Evapotranspiration (PET). However, temperature rise and evaporation associated with global warming cannot be ignored to evaluate drought; therefore, SPEI appears to be better than SPI in terms of drought monitoring (Mathbout et al., 2018).

This study aimed to investigate the temporal variation of drought events of the Seyhan and Ceyhan basins in Turkey, based on data from 14 meteorological stations gathered between January 1989 and July 2020, using Standardized Precipitation Index and Standardized Precipitation Evapotranspiration Index.

\section{Materials and Methods}

\section{Study Area}

The Seyhan and Ceyhan basins lie between $35^{\circ} .40^{\prime}$ to $39^{\circ} .25^{\prime} \mathrm{N}$ latitudes and $34^{\circ} .40^{\prime}$ to $37^{\circ} .80^{\prime} \mathrm{E}$ longitudes with an area of $43.840 \mathrm{~km}^{2}$. In particular, Cukurova delta plain is located in the south of these basins, which the biggest delta plain of Turkey. Therefore, drought analysis is of great importance in these basins (Gumus and Algin, 
2017). The northern parts of the Seyhan basin are in the Central Anatolia Region, the central and southern parts are in the Mediterranean Region (Figure 1). The most important settlements in the Seyhan basin are the cities of Kayseri, Nigde, Sivas, Mersin and Adana. The Seyhan basin is adjacent to Kizilirmak, Konya and the Eastern Mediterranean basins in the west, the Ceyhan and Euphrates River in the east (Republic of Turkey Ministry of Forestry and Water Affairs, 2017). The Ceyhan basin is neighbour to Seyhan Basin in the northwest, the Asi basin which is in the south and the Euphrates River basin which is in the northeast. The Gulf of Iskenderun surrounds the south part of the Seyhan basin. The Ceyhan basin area covers three main provinces (Kahramanmaras, Osmaniye and Adana). The Seyhan-Ceyhan Basins have similar climate conditions (Tanriverdi et al., 2010). In the lower parts of these basins, the climate is mainly the Mediterranean, while in the central and upper parts of the basins, the climate is mainly continental.

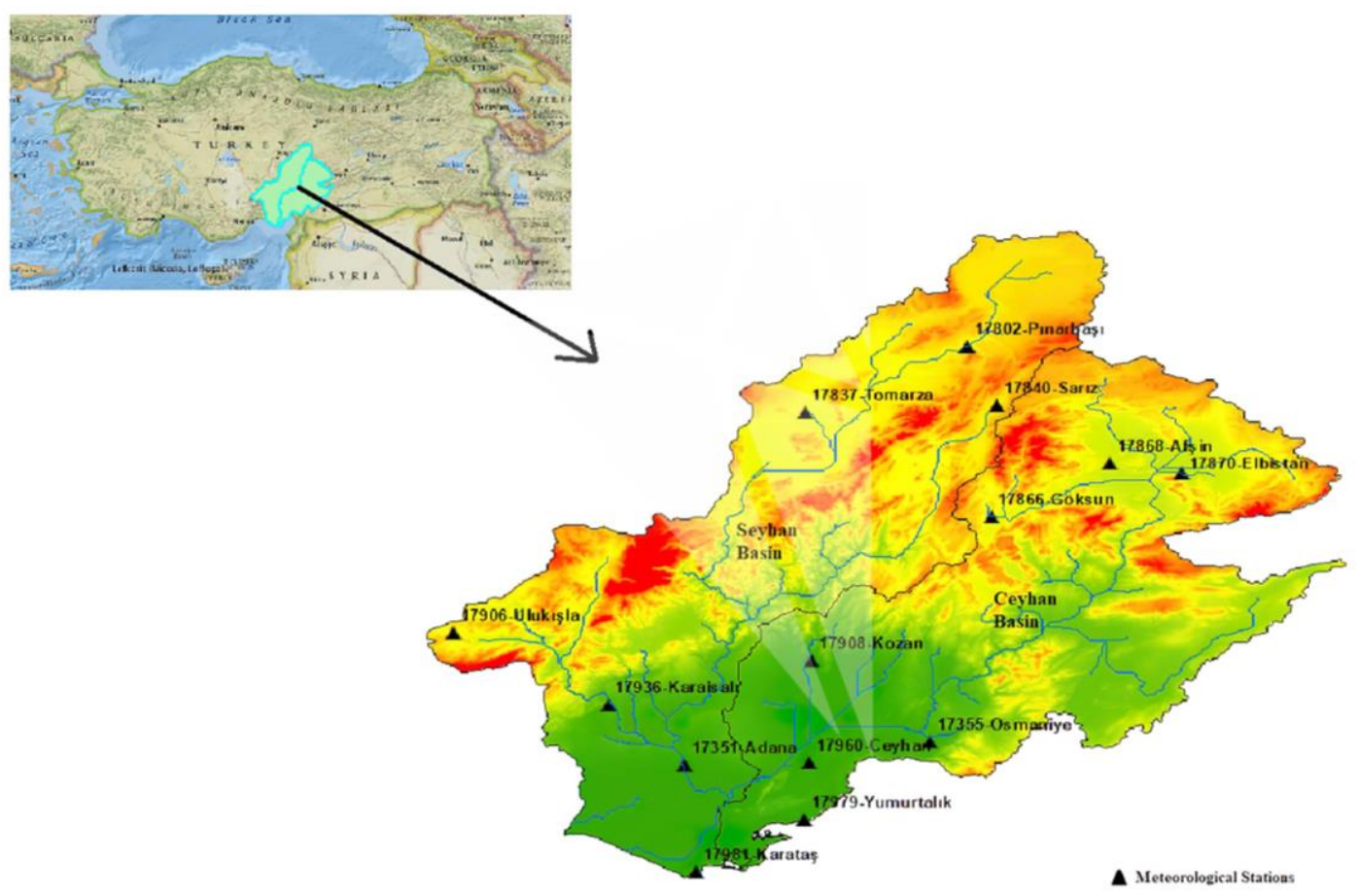

Figure 1. The Seyhan-Ceyhan basins' geographical locations and distribution of the spatial meteorological stations

\section{Data Used}

Drought analyses were performed using monthly data collected from 14 meteorological stations. Meteorological data were obtained from the Ministry of Agriculture and Forestry and General Directorate of Meteorology. The missing data was filled with the help of CRU-TS 4.04 (Climatic Research Unit Timeseries). As presented in Table 1, the geographical characteristics of meteorological stations, observation periods, monthly average temperatures and annual average precipitation values were considered in the drought analyses. SPI and SPEI analyses were conducted using observation data from January 1989 to July 2020. 
Table 1. Geographical features of meteorological stations, monthly average temperatures and annual average precipitation values for meteorological stations selected between January 1989 and July 2020

\begin{tabular}{|c|c|c|c|c|c|c|c|}
\hline Station ID & $\begin{array}{c}\text { Station } \\
\text { name }\end{array}$ & $\begin{array}{l}\text { Altitude } \\
\quad \text { (m) }\end{array}$ & $\begin{array}{c}\text { Latitude } \\
\text { (N) }\end{array}$ & $\begin{array}{l}\text { Longitude } \\
\text { (E) }\end{array}$ & $\begin{array}{c}\text { Monthly } \\
\text { average } \\
\text { Tmin }\left({ }^{\circ} \mathrm{C}\right)\end{array}$ & $\begin{array}{c}\text { Monthly } \\
\text { average } \\
\text { Tmax }\left({ }^{\circ} \mathrm{C}\right)\end{array}$ & $\begin{array}{c}\text { Annual } \\
\text { average } \\
\text { rainfall } \\
(\mathrm{mm})\end{array}$ \\
\hline \multicolumn{8}{|c|}{ Seyhan Basins Stations } \\
\hline 17351 & Adana & 23 & 37.0041 & 35.3443 & 14.6 & 25.5 & 655 \\
\hline 17802 & Pinarbasi & 1542 & 38.7224 & 36.3924 & 1.2 & 15 & 392 \\
\hline 17837 & Tomarza & 1402 & 38.4522 & 35.7912 & 0.6 & 16.2 & 380 \\
\hline 17840 & Sariz & 1599 & 38.4781 & 36.5035 & 0.9 & 14.8 & 485 \\
\hline 17936 & Karaisali & 240 & 37.2505 & 35.0628 & 14.1 & 24.3 & 862 \\
\hline 17981 & Karatas & 22 & 36.5683 & 35.3894 & 15.5 & 23.5 & 777 \\
\hline 17906 & Ulukisla & 1453 & 37.548 & 34.4867 & 4.4 & 16.4 & 326 \\
\hline \multicolumn{8}{|c|}{ Ceyhan Basins Stations } \\
\hline 17355 & Osmaniye & 94 & 37.1021 & 36.2539 & 12.7 & 24.7 & 811 \\
\hline 17960 & Ceyhan & 48 & 37.0132 & 35.8055 & 12.6 & 25 & 719 \\
\hline 17979 & Yumurtalik & 34 & 36.7801 & 35.7903 & 15.2 & 24.3 & 791 \\
\hline 17866 & Goksun & 1344 & 38.024 & 36.4823 & 2.3 & 16.5 & 555 \\
\hline 17868 & Afsin & 1230 & 38.2405 & 36.919 & 4.4 & 17.6 & 415 \\
\hline 17870 & Elbistan & 1137 & 38.2038 & 37.1892 & 4.4 & 18.6 & 379 \\
\hline 17908 & Kozan & 112 & 37.4337 & 35.8188 & 15.1 & 25.7 & 796 \\
\hline
\end{tabular}

\section{Methods}

\section{Standardized Precipitation Index}

SPI is a drought index designed by McKee et al. (1993) and it is an essential tool in identifying periodic meteorological droughts using specific time-precipitation data as input parameter. SPI drought classes are obtained from precipitation series with (standard normal distribution) Gauss distribution (Gurler, 2017). Nevertheless, the probability distribution function of precipitation and data series does not usually match the normal distribution. The probability distribution that performs best on rainfall data is the Gamma probability distribution. According to McKee et al. (1993), distribution functions obtained from precipitation data are converted to Gamma probability distribution functions in the SPI method. The precipitation prediction probabilities derived from the Gamma probability distribution function are converted into normalized standard precipitation series with the help of the reverse standard normal distribution function. As a result, Standardized Precipitation Index is calculated using mean and variance.

SPI is measured as the ratio of the difference between the current and the average precipitation amounts to the standard deviation at a given time (McKee et al., 1993):

$$
\mathrm{SPI}=\frac{x_{i}-x_{j}}{\sigma}
$$

where,

$x_{i}$ : Current Precipitation

$x_{j}$ : Average Precipitation

$\sigma:$ Standart Deviation 
Table 2 summarizes possible explanations for wet or dry conditions using the cumulative probabilities for the various SPI / SPEI values and the resulting SPI / SPEI values.

Table 2. Classification of SPI / SPEI values

\begin{tabular}{c|c}
\hline SPI-SPEI & Classification \\
\hline$\geq 2.00$ & Extremely Wet \\
1.5 to 1.99 & Severely Wet \\
1.0 to 1.49 & Moderately Wet \\
0.5 to 0.99 & Slightly Wet \\
-0.49 to 0.49 & Near Normal \\
-0.99 to -0.5 & Mild Dry \\
-1.49 to -1.0 & Moderately Dry \\
-1.99 to -1.5 & Severely Dry \\
$\leq-2.00$ & Extremely Dry \\
\hline
\end{tabular}

\section{Standardized Precipitation Evapotranspiration Index}

SPEI is designed by Vicente-Serrano et al. (2010). SPEI method provides the point and spatial distribution by including the temperature, evaporation and perspiration parameters in addition to the drought calculations made using only precipitation data as the SPI method does. Thus, converting the original values to standard units, it provides spatial-temporal comparison and evaluation as a multi-temporal structure (LorenzoLacruz et al., 2010; Vicente-Serrano et al., 2010; Beguería et al., 2014).

SPEI method, developed to overcome the limitations of the SPI method, can include factors like Palmer Drought Severity Index (PDSI), temperature and evaporation. The multiple-temporal structure of SPI method also allows inspections in long-term (6-1224 month periods) projections (Republic of Turkey Ministry of Forestry and Water Affairs General Directorate of Water Management Department of Flood and Drought Management, 2015). The variation in rainfall is specified using the log-logistical distribution as standard (Liu et al., 2015). In applications performed in many parts of the world, a good relationship was between log-logistic distribution and rainfall variation series in different time scales and climatic areas. This is important for the effective use of the SPEI method (Vicente-Serrano et al., 2010).

SPEI standardizes the difference between Potential Evapotranspiration (PET) and precipitation $(P)$, defining the degree of distortion of humid or dry conditions. SPEI is calculated by the potential evaporation data collected in specific periods with the difference between weekly or monthly rainfall and corresponding to a probability distribution function (Beguería et al., 2014). SPEI can effectively identify the water deficit with several time scales reflecting the lag relationship of different water sources, rainfall and evaporation (Liu et al., 2015).

The deficiency difference between rainfall, evapotranspiration and humidity cannot be positive. This is common in semi-dry and dry zones where the difference in moisture deficiency is negative. So, a three-parameter distribution is required to model open values (Hernandez and Uddameri, 2014). Three-parameter log-logistic distribution is more generally preferred than the normal distribution (Vicente-Serrano et al., 2010; Zambreski, 2016). While negative values of SPEI express aridity, positive values express above-average humidity and normal conditions. 


\section{Calculating SPEI:}

(1) SPEI is measured as the difference $(D)$ between Potential Evapotranspiration (PET) and Precipitation $(P)$ on a monthly (or weekly) basis. PET is computed by the Hargreaves equation with limited data requirements and has no internal limitations of the Thornthwaite equation, which is similar to the standard Food and Agriculture Organization - Penman-Monteith Method (FAO PM) equation (Hargreaves, 1994; Hargreaves and Allen, 2003):

$$
D_{i}=P_{i}-P E T_{i}
$$

where $D_{i}$ is the water surplus or deficit for the analyzed month $i$.

(2) The next step is to compute the cumulative difference in different time scales between Precipitation $(P)$ and PET. The computed $D_{i}$ values are collected at different time scales with the same method as that for the SPI. For example, the cumulative difference can be calculated for one month in a specific year on a 12-month time scale as:

$$
\begin{gathered}
\text { If } j<k X_{i, j}^{k}=\sum_{l=13-k+j}^{12} D_{i-1, l}+\sum_{l=1}^{j} D_{i, l} \\
\text { If } j \geq k X_{i, j}^{k}=\sum_{l=j-k+1}^{j} D_{i, l}
\end{gathered}
$$

where $D_{i, l}$ is the $P$ - PET difference at the first month of year i, in millimeter and $X_{i, j}^{k}$ is the cumulative difference for a given $k$ timescale in month $j$ and year $i$.

(3) Normalization of $X_{i, j}^{k}$; because data can have negative values of $X_{i, j}^{k}$ in the unique data array. Therefore, the three parameters log-logistics probability capacity distribution is used by SPEI. The cumulative function $F(x)$ of the logistic probability distribution for the data series of all time scales (Beguería et al., 2014).

$$
F(x)=\left[1+\left(\frac{a}{x-\gamma}\right)^{\beta}\right]^{-1}
$$

The log-logistic distribution parameters could be computed by several methods. Among them, the process of possible-weighted moments is the most dependable and easily applicable method. Log-logistics parameters are necessary for realistic drought analysis and observations, as they provide temporal and spatial comparability of drought indices ( $\mathrm{Yu}$ et al., 2014). $\alpha, \beta$ and $\gamma$ are scale, shape and origin parameters, respectively and these could be computed with the equations used by Vicente-Serrano et al. (2010) SPEI calculation equations as $P$ value are as follows:

$$
P=1-F(x)
$$


where $P$ is the probability of exceeding a determined $X_{i, j}^{k}$ value is exceeded.

$$
\begin{aligned}
& \text { If } P \leq 0.5, W=\sqrt{-2 \ln (P)}, \quad \text { SPEI }=W-\frac{C_{0}+C_{1} W+C_{2} W^{2}}{1+d_{1} W+d_{2} W^{2}+d_{3} W^{3}} \\
& \text { If } P>0.5, W=\sqrt{-2 \ln (1-P)}, \quad \text { SPEI }=\frac{C_{0}+C_{1} W+C_{2} W^{2}}{1+d_{1} W+d_{2} W^{2}+d_{3} W^{3}}-W
\end{aligned}
$$

where the variables $\mathrm{C}_{0}=2.515517, \mathrm{C}_{1}=0.802853, \mathrm{C}_{2}=0.010328$, and $\mathrm{d}_{1}=1.432788$, $\mathrm{d}_{2}=0.189269, \mathrm{~d}_{3}=0.001308$ are constants (Vicente-Serrano et al., 2010).

The computed values of SPEI in the basin are used to examine the characteristics of dry and wet events in the basin according to their occurrence time, severity and frequency of occurrence. These values are categorized as in Table 2. The threshold ranges used are SPEI $\leq-1$ for the dry event and SPEI $\geq 1$ for the wet event. The period of an event is the time (months) during which the SPEI is equal to or less than the consecutive cut-off level (Gao et al., 2017; Polong et al., 2019).

\section{Results and Discussion}

Drought analysis was performed using meteorological data in the Seyhan-Ceyhan basins. SPI and SPEI are calculated for 3-, 4-, 6-, 12-month periods using meteorological data from January 1989 to July 2020. While calculating SPI only precipitation data was used but SPEI was calculated using precipitation data, values of minimum and maximum temperature. SPI and SPEI values were evaluated according to the drought classes in Table 2. However, since the direct evaporation data of the stations in the basins are not complete and there are no continuous data records, SPEI analysis was done with temperature data. Distributions of SPI and SPEI according to 3-, 4-, 6and 12-month analyses are shown in Figures 2 and 3. The climatic conditions of the basins generally reveal similar characteristics and the yearly-based SPI and SPEI values appear to be consistent as shown Figure 3. Due to the compatibility of the topographic features and precipitation data of these basins, a joint evaluation was made for basins.

The coefficient of determination $\left(\mathrm{R}^{2}\right)$ between annual SPI and SPEI drought indices was found to be 0.954 for the analysis of approximately 30 years' meteorological data of the Seyhan and Ceyhan basins (Figure 4).

Considering period between January 1989 and July 2020, the highest degree of drought values was found between March and July 1989 in the SPI and SPEI evaluations calculated for 3-month periods. Continuous long-term drought was observed between November 2013-June 2014. As a result of the drought assessments using SPI values calculated based on 3-months periods indicated that $3.7 \%, 3.4 \%, 7.7 \%$ and $16.4 \%$ of the periods were to be Extremely Dry, Severely Dry, Moderately Dry, Mild Dry. The same assessment for SPEI showed 1.6\%, 4.2\%, 10.6\% and $15.4 \%$ of the whole period were to be Extremely Dry, Severely Dry, Moderately Dry, Mild Dry. When the SPI was evaluated for each season, it was found that 20 months between September 2011 and July 2014 and 15 months between November 2015 and December 2017 were dry. Seasonal SPEI assessments were found to be dry for 21 months between 
September 2011 and July 2014 and for 18 months between November 2015 and December 2017.
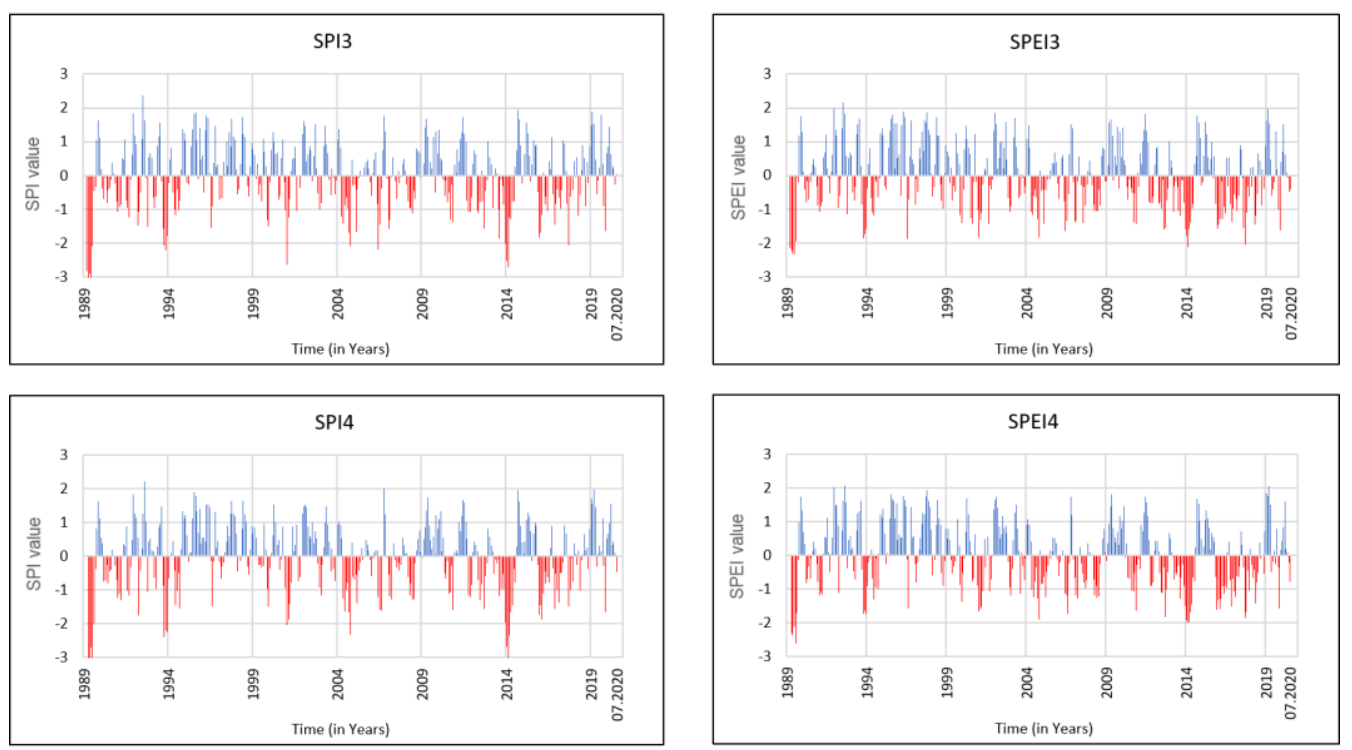

Figure 2. Result of SPI and SPEI values at 3-month, 4-month time scales between January 1989 and July 2020 time frame in study area
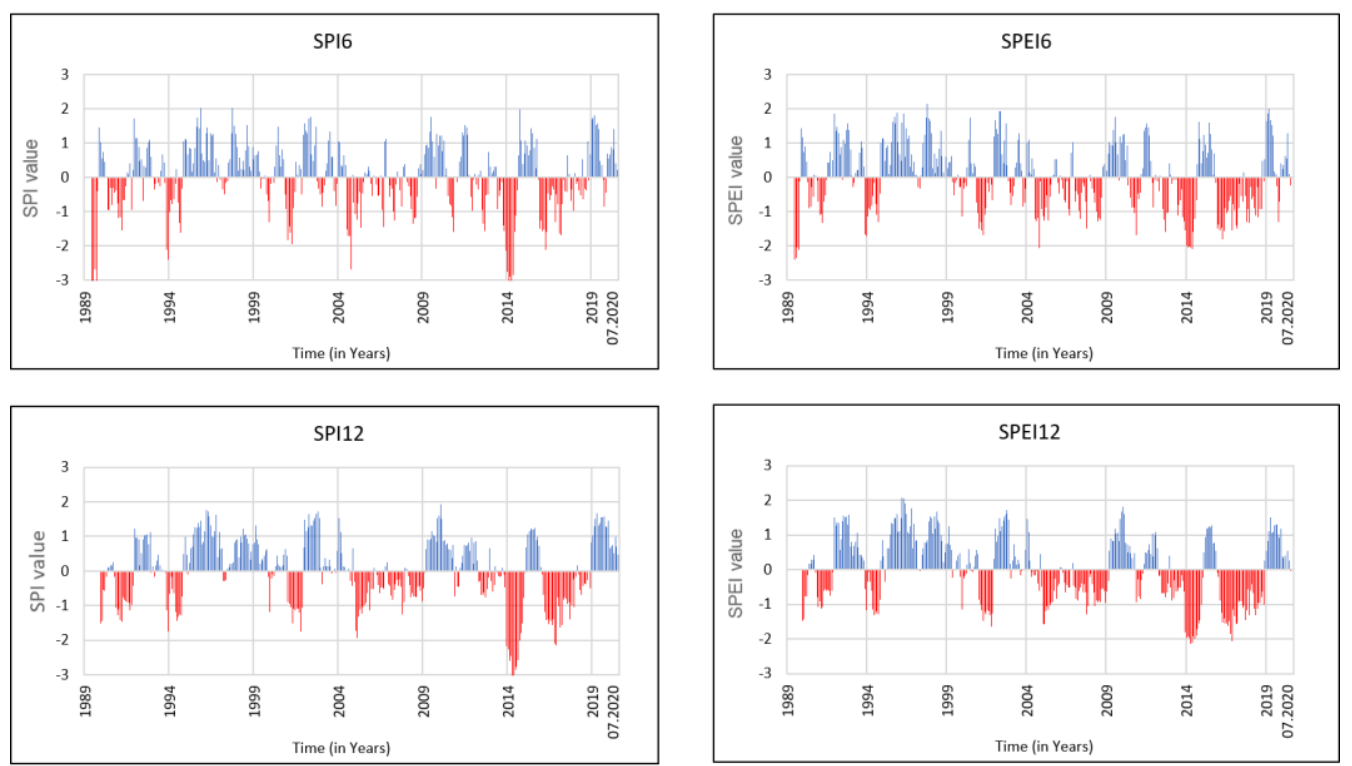

Figure 3. Result of SPI and SPEI values at 6-month, 12-month time scales between January 1989 and July 2020 time frame in study area

When the SPI and SPEI values were evaluated by taking 4-month periods, it was determined that the period with the highest degree of drought was between April and August 1989. When the SPI is calculated by taking 4-month periods and drought analyses are made, $3.5 \%, 4.0 \%, 9.3 \%$ and $10.9 \%$ of the time period was determined as Extremely Dry, Severely Dry, Moderately Dry and Mild Dry, respectively when 
compared to the total time examined. Analyses using the same periods for SPEI showed that $1.3 \%, 5.9 \%, 9.6 \%$ and $16.5 \%$ of the total time were determined as Extremely Dry, Severely Dry, Moderately Dry and Mild Dry, respectively. In the 4-month evaluations of the SPI, it was found that it was dry for 17 months between May 2012-July 2014 and dry for 15 months between December 2015-December 2017. In the 4-month evaluations of SPEI, it was determined that 19 months between May 2012 and July 2014 and 18 months between December 2015 and December 2017 were dry.

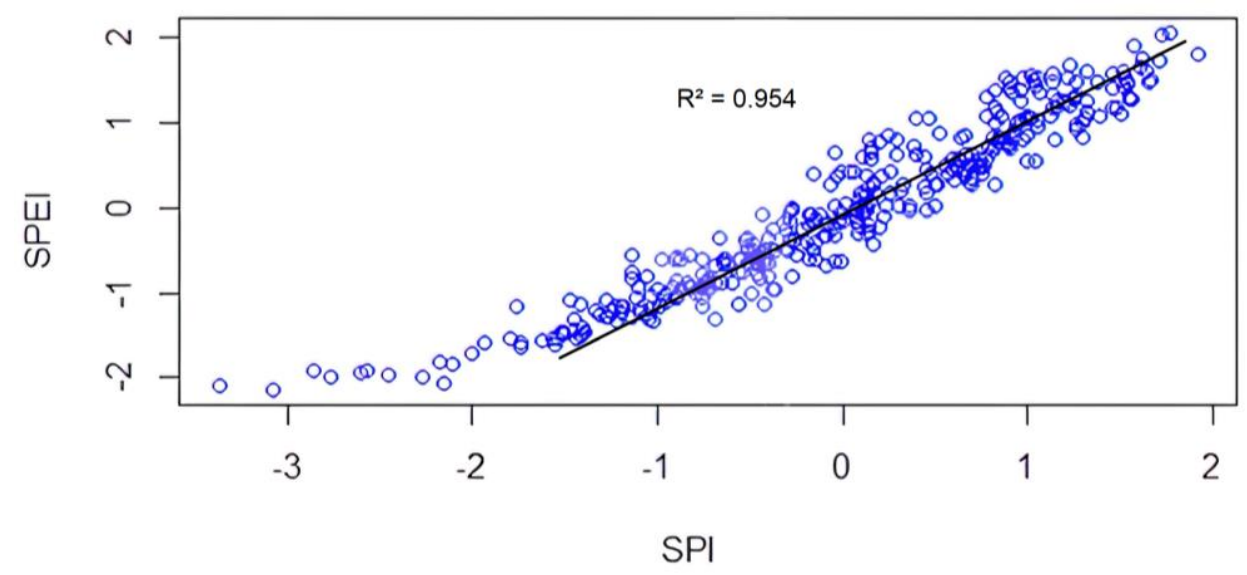

Figure 4. Scatter plot showing linear relationship between annual SPI and SPEI

6-month based evaluations of SPI and SPEI revealed that the period with the highest severity of drought was between June-September 1989. SPI values calculated for 6month periods further showed that $3.7 \%, 4.5 \%, 5.9 \%$ and $13.1 \%$ of the time interval examined within the scope of the project were Extremely Dry, Severely Dry, Moderately Dry and Mild Dry months, respectively and between October 2013-July 2014 were determined as the period with the highest degree of drought. Based on SPEI's 6-month-based assessment, the longest continuous dry months are from December 2015 to April 2017. According to the calculated SPEI values, 2.4\%, 4.0\%, $10.7 \%$ and $15.8 \%$ of all months were found to be Extremely Dry, Severely Dry, Moderately Dry and Mild Dry months, respectively. For SPI, 24 months between July 2004 and September 2008, 13 months between July 2012 and July 2017 and 13 months between December 2015 and April 2017 were determined as dry months. When the same evaluation was made for 12-month periods for SPI, 27 months between January 2005-2009, 19 months between June 2012-December 2014 and 24 months between February 2016-May 2018 were observed as dry periods.

In the evaluations of SPI with 12-month data, the highest drought severity range was found between December 2013-2014. As a result of SPI's 12-month drought evaluations, when it is compared with the total number of months, 3.3\%, 3.3\%, 10.1\% and $13.3 \%$ of the months were determined as Extremely Dry, Severely Dry, Moderately Dry and Mild Dry, respectively. On the other hand, according to the evaluation made for SPEI with the same data, the long continuous dry months are the months between February 2016 and October 2017. SPEI's 12-month data assessments showed that the largest drought severity was between November 2013 and December 2014. As a result of SPEI's 12-month drought evaluations, $0.8 \%, 5.2 \%, 12.0 \%$ and $18.2 \%$ of the months were determined as Extremely Dry, Severely Dry, Moderately Dry and Mild Dry, 
respectively. Also, the longest dry months, according to SPEI, are from February 2016 to November 2018.

The ratio of dry periods to total periods in the drought evaluations of the study area, in the 3-month evaluations SPI-3 31.2\% and SPEI-3 31.8\%, in the 4-month evaluations SPI-4 27.7\% and SPEI-4 33.3\%, in the 6-month evaluations SPI-6 27.2\% and SPEI-6 $32.9 \%$, in 12-month evaluations SPI-12 30.0\% and SPEI-12 36,2\% were determined. According to the monthly evaluations, it was seen that SPI determined the number of extremely dry months higher than SPEI. On the other hand, SPEI found the total number of dry months higher than SPI. In some years, differences were observed between SPI and SPEI regardless of time scale. SPEI has identified longer drought periods than SPI. The fact that SPEI determines the drought duration longer than SPI can be explained by the fact that evapotranspiration places demand on available water and its effect is felt most under water scarcity conditions. The results show that although decreased precipitation is the main driver of drought, the effect of temperature through evaporative water demand plays a role in determining droughts. Moreover, an increase in the number of Severely Dry, Moderately Dry, Mild Dry months was observed in the SPEI assessments. When the evapotranspiration effect was calculated, it was observed that the total number of dry months was high. Compared to SPEI, drought thresholds peak on more SPI graphs. Most of the wet months in these time frames are months that are classified as slightly and moderately wet. In the long-term drought analysis, SPEI reflects the drought impacts more successfully than SPI.

Vicente-Serrano et al. (2010) proved that SPI could not determine the role of temperature rise in future drought conditions. They explained the potential impacts of temperature changes and excessive temperatures in terms of global warming. Although determining the effect of evapotranspiration in drought conditions is very complex, they emphasized its inclusion in drought index calculations. Considering the additional data requirements of SPEI, it is more likely that SPI can be used to identify, analyze and monitor droughts in any climatic zone of the world (Vicente-Serrano et al., 2010; Beguería et al., 2014). Mathbout et al. (2018) confirmed the effect of PET index in calculating the severity of drought compared to the SPEI analysis. Stagge et al. (2014) stated in their research that the SPI proposed by the World Meteorological Organization (WMO) has significant potential as a variant of the SPEI meteorological drought index. As a justification, they showed that SPEI provides a more comprehensive water asset measurement and uses climatic water balance. Li et al. (2015) characterized drought conditions in southwestern China using SPEI and SPI in their study. In their study, they performed a correlation analysis between two remote sensing-based drought indices to study the performance of SPEI and SPI. They also found that SPEI gave better results than SPI. Nedealcov et al. (2015) compared the SPEI and SPI indices for the temporal and spatial distributions of drought in three and six-month periods for Moldova between 1980-2014 time scale. They stated that both indices gave similar shapes in temporal distributions, but there were differences between the two indices due to the fact that the SPEI values in terms of drought duration and severity use not only precipitation but also evapotranspiration. Danandeh Mehr and Vaheddoost (2020) stated that they observed similar drought events in their short-term (3-month) analysis between SPI and SPEI. In particular, SPI and SPEI found inconsistency between each other at 6 and 12 month time frames. Tefera et al. (2019) revealed that SPI can be used instead of SPEI at all time scales in their study. Therefore, they indicated that it is safer to use the SPI to 
assess the drought in the study area at all studied time scales in the absence of temperature data and/or appropriate analysis tools to performing the SPEI.

Considering the annual values for SPI-12 and SPEI-12, 2014 was the driest year compared to the years examined in the drought classification. Drought intensity and the number of dry months in 2014 are remarkable in both indices. According to the SPI-12 and SPEI-12 annual drought classification results shown in Figure 3, the analysis results of the driest and wettest years are given in detail in Table 3a-b. In SPI-12 analyses, the driest years after 2014 were observed as 2005, 2016, 2001 and 2017, respectively. For SPEI-12, the driest years after 2014 were observed as 2016, 2017, 2001, 2005, respectively.

Table 3-a. Classification of the driest years to their months' drought characteristic according to SPI-12 and SPEI-12 analysis of study area between January 1989 and July 2020

\begin{tabular}{c|c|c|c|c|c}
\hline \multicolumn{7}{c}{ SPEI-12 Analysis Result of the Driest Years } \\
\hline Year & Extremely Dry & Severely Dry & Moderately Dry & Mild Dry & Near Normal \\
\hline 2014 & 2 & 8 & 2 & & \\
2016 & 1 & 5 & 4 & 1 & 1 \\
2017 & & 2 & 6 & 4 & 1 \\
2001 & & 1 & 9 & 1 & 2 \\
2005 & & 2 & 4 & 4 & Near Normal \\
\hline \multicolumn{7}{c}{ SPI-12 Analysis Result of the Driest Years } \\
\hline Year & Extremely Dry & Severely Dry & Moderately Dry & Mild Dry & \\
2014 & 9 & 2 & 4 & 1 & 1 \\
2005 & 2 & 5 & 5 & 2 & 1 \\
2016 & 2 & 2 & 7 & 3 & \\
2001 & & 2 & 3 & 6 & \\
2017 & & 2 &
\end{tabular}

Table 3-b. Classification of the wettest years to their months' drought characteristic according to SPI-12 and SPEI-12 analysis of study area between January 1989 and July 2020

\section{SPEI-12 Analysis Result of the Wettest Years}

\begin{tabular}{c|c|c|c|c|c}
\hline Year & Extremely Wet & Severely Wet & Moderately Wet & Slightly Wet & Near Normal \\
\hline 1996 & 2 & 3 & 6 & 1 & \\
1992 & & 4 & 5 & 3 & \\
2019 & & 1 & 8 & 3 & \\
2002 & & 3 & 6 & 2 & 1 \\
1998 & & 2 & 6 & 3 & 1 \\
\hline
\end{tabular}

SPI-12 Analysis Result of the Wettest Years

\begin{tabular}{c|c|c|c|c|c}
\hline Year & Extremely Wet & Severely Wet & Moderately Wet & Slightly Wet & Near Normal \\
\hline 2019 & & 5 & 7 & & \\
2002 & & 5 & 6 & & 1 \\
1996 & & 4 & 4 & 3 & 1 \\
2015 & & 2 & 6 & 5 & 1 \\
2009 & & & 3 & 5 & 2 \\
\hline
\end{tabular}


SPI-12 annual data identified 2019 as the wettest year among the years analyzed in the drought classification. Except for 2019, the wettest years were observed as 2002, 1996, 2015 and 2009, respectively. According to SPEI-12, 1996 was the wettest year compared to the years examined in the drought classification. Other than 1996, the wettest years were 1992, 2019, 2002 and 1998, respectively. SPI and SPEI differed in annual estimates when evaporation was calculated based on the temperature factor and sorted by rainy and dry years. Both indices found the same dry years but found the wettest years mildly different from each other.

The use of potential evapotranspiration in SPEI represents the water balance of a zone and therefore the severity of drought better than SPI. The weakness of analysis with SPEI is that it may not respond immediately to rapidly developing and short-term drought events. The strongest aspect of the SPI method is that it can be computed using just rainfall data. The SPI is partially inefficient as it uses only precipitation data as input and does not take into account the total water balance of a region and the temperature component that is important to water use. SPEI and SPI indices should be analyzed by comparing drought monitoring maps produced using remote sensing methods. In this way, a more comprehensive analysis can be made with both temporal and spatial drought analysis.

\section{Conclusions}

In this study, multiple monthly-based (3-, 4-, 6-, 12- month based) drought analyses were conducted based on SPI and SPEI drought indices calculated from meteorological data of the Seyhan and Ceyhan basins between January 1989 and July 2020 and the calculated SPI and SPEI results were compared. Drought indices used in the study are widely used throughout the world as a tool in hydrological, meteorological and agricultural drought analyses, defining long-term drought events, determining the beginning and ending times and measuring the severity. These analyses reveal that increase of dry months' number and duration after the 2000s is remarkable. The results of these analysis show that there is a significant drought risk when analyzed on an annual basis. The non-dry years in the basins are mainly in the moderately wet class. Calculated drought indices reveal that 2014 was the driest year on an annual basis. Other factors affecting the increase in drought in the last decade should be investigated and the environmental, economic and social effects of drought need to be determined in detail. A drought mitigation plan is needed in the area to promote the sustainable use of agricultural and natural water resources and mitigate the effects of future drought events. In order to determine regional droughts, analyses should be continued with remote sensing images and input parameters measured at stations, e.g., humidity, solar radiation.

\section{REFERENCES}

[1] Ahsan, M. M. (2020a): Desertification in the OIC Member Countries: Factors, Challenges and the Way Forward. - Journal of Bartin Faculty of Forestry 22(2): 642-653. DOI: $10.24011 /$ barofd.731741.

[2] Ahsan, M. M. (2020b): Climate Change Adaptation-Based Strategies on Water and Its Security: A Study on Dhaka and Ankara. - The Journal of Security Sciences Special 
Volume (International Security Congress Special Issue), pp. 79-93. DOI: 10.28956/gbd.695924.

[3] Alley, W. M. (1984): The Palmer Drought Severity Index: Limitations and Assumptions. - Journal of Climate and Applied Meteorology 23(7): 1100-1109. DOI: 10.1175/15200450(1984)023<1100:tpdsil>2.0.co;2.

[4] Beguería, S., Vicente-Serrano, S. M., Reig, F., Latorre, B. (2014): Standardized precipitation evapotranspiration index (SPEI) revisited: parameter fitting, evapotranspiration models, tools, datasets and drought monitoring. - International Journal of Climatology 34(10): 3001-3023. DOI: 10.1002/joc.3887.

[5] Chang, T. J., Kleopa, X. A. (1991): A Proposed Method for Drought Monitoring. Journal of the American Water Resources Association 27(2): 275-281. DOI: 10.1111/j.1752-1688.1991.tb03132.x.

[6] Danandeh Mehr, A., Vaheddoost, B. (2020): Identification of the trends associated with the SPI and SPEI indices across Ankara, Turkey. - Theoretical and Applied Climatology 139(3-4): 1531-1542. DOI: 10.1007/s00704-019-03071-9.

[7] Gao, X., Zhao, Q., Zhao, X., Wu, P., Pan, W., Gao, X., Sun, M. (2017): Temporal and spatial evolution of the standardized precipitation evapotranspiration index (SPEI) in the Loess Plateau under climate change from 2001 to 2050. - Science of The Total Environment 595: 191-200. DOI: 10.1016/j.scitotenv.2017.03.226.

[8] Gumus, V., Algin, H. M. (2016): Meteorological and hydrological drought analysis of the Seyhan-Ceyhan River Basins, Turkey. - Meteorological Applications 24(1): 62-73. DOI: 10.1002/met.1605.

[9] Gurler, C. (2017): Beysehir and Konya-Cumra-Karapinar Sub-Basins. - Hydrological Drought Assessment with the Standardized Indices Approach. Publication in Turkish.

[10] Hargreaves, G. H. (1994): Defining and Using Reference Evapotranspiration. - Journal of Irrigation and Drainage Engineering 120(6): 1132-1139. DOI: $10.1061 /($ asce $) 0733-$ 9437(1994)120:6(1132).

[11] Hargreaves, G. H., Allen, R. G. (2003): History and Evaluation of Hargreaves Evapotranspiration Equation. - Journal of Irrigation and Drainage Engineering 129(1): 53-63. DOI: 10.1061/(asce)0733-9437(2003)129:1(53).

[12] Hernandez, E. A., Uddameri, V. (2014): Standardized precipitation evaporation index (SPEI)-based drought assessment in semi-arid south Texas. - Environmental Earth Sciences 71(6): 2491-2501. DOI: 10.1007/s12665-013-2897-7.

[13] Homdee, T., Pongput, K., Kanae, S. (2016): A comparative performance analysis of three standardized climatic drought indices in the Chi River basin, Thailand. - Agriculture and Natural Resources 50(3): 211-219. DOI: 10.1016/j.anres.2016.02.002.

[14] Li, X., He, B., Quan, X., Liao, Z., Bai, X. (2015): Use of the Standardized Precipitation Evapotranspiration Index (SPEI) to Characterize the Drying Trend in Southwest China from 1982-2012. - Remote Sensing 7(8): 10917-10937. DOI: 10.3390/rs70810917.

[15] Liu, X., Wang, S., Zhou, Y., Wang, F., Li, W., Liu, W. (2015): Regionalization and Spatiotemporal Variation of Drought in China Based on Standardized Precipitation Evapotranspiration Index (1961-2013). - Advances in Meteorology.

DOI: $10.1155 / 2015 / 950262$.

[16] Lorenzo-Lacruz, J., Vicente-Serrano, S. M., López-Moreno, J. I., Beguería, S., GarcíaRuiz, J. M., Cuadrat, J. M. (2010): The impact of droughts and water management on various hydrological systems in the headwaters of the Tagus River (central Spain). Journal of Hydrology 86(1-4): 13-26. DOI: 10.1016/j.jhydrol.2010.01.001.

[17] Mathbout, S., Lopez-Bustins, J. A., Martin-Vide, J., Bech, J., Rodrigo, F. S. (2018): Spatial and temporal analysis of drought variability at several time scales in Syria during 1961-2012. - Atmospheric Research 200: 153-168.

DOI:10.1016/j.atmosres.2017.09.016. 
[18] McKee, T. B., Doesken, N. J., Kleist, J. (1993): The relationship of drought frequency and duration to time scales. - Paper presented at 8th Conference on Applied Climatology, Am. Meteorol. Soc., Anaheim, California, pp. 17-22.

[19] Mishra, A. K., Singh, V. P. (2010): A review of drought concepts. - Journal of Hydrology 391(1-2): 202-216. DOI: 10.1016/j.jhydrol.2010.07.0121.

[20] Nedealcov, M., Răileanu, V., Sîrbu, R., Cojocari, R. (2015): The Use of Standardized Indicators (SPI and SPEI) In Predicting Droughts Over the Republic Of Moldova Territory. - Present Environment and Sustainable Development 9(2): 149-158. DOI: 10.1515/pesd-2015-0032.

[21] Olukayode Oladipo, E. (1985): A comparative performance analysis of three meteorological drought indices. - Journal of Climatology 5(6): 655-664. DOI: $10.1002 /$ joc.3370050607.

[22] Polong, F., Chen, H., Sun, S., Ongoma, V. (2019): Temporal and spatial evolution of the standard precipitation evapotranspiration index (SPEI) in the Tana River Basin, Kenya. Theoretical and Applied Climatology 138(1-2): 777-792. DOI: 10.1007/s00704-01902858-0.

[23] Republic of Turkey Ministry of Forestry and Water Affairs (2017): Project on Preparation of Seyhan Basin Sectoral Water Allocation Plan. - Publication in Turkish.

[24] Republic of Turkey Ministry of Forestry and Water Affairs General Directorate of Water Management Department of Flood and Drought Management (2015): Akarcay Basin Drought Management Plan Drought Indices, Indicators and Threshold Values Detection Report. - publication in Turkish.

[25] Stagge, J. H., Tallaksen, L. M., Xu, C. Y., Van Lanen, H. A. J. (2014): Standardized precipitation-evapotranspiration index (SPEI): Sensitivity to potential evapotranspiration model and parameters. - In: IAHS-AISH Proceedings and Reports 363: 367-373.

[26] Tanrıverdi, Ç., Alp, A., Demirkıran, A. R., Üçkardeş, F. (2009): Assessment of surface water quality of the Ceyhan River basin, Turkey. - Environmental Monitoring and Assessment 167(1-4): 175-184. DOI: 10.1007/s10661-009-1040-4.

[27] Tao, H., Borth, H., Fraedrich, K., Su, B., Zhu, X. (2013): Drought and wetness variability in the Tarim River Basin and connection to large-scale atmospheric circulation. International Journal of Climatology 34(8): 2678-2684. DOI: 10.1002/joc.3867.

[28] Tefera, A. S., Ayoade, J. O., Bello, N. J. (2019): Comparative analyses of SPI and SPEI as drought assessment tools in Tigray Region, Northern Ethiopia. - SN Applied Sciences 1(10): 1265. DOI: 10.1007/s42452-019-1326-2.

[29] Vicente-Serrano, S. M., Beguería, S., López-Moreno, J. I. (2010): A Multiscalar Drought Index Sensitive to Global Warming: The Standardized Precipitation Evapotranspiration Index. - Journal of Climate 23(7): 1696-1718. DOI: 10.1175/2009jcli2909.1.

[30] Wang, Y., Liu, G., Guo, E. (2019): Spatial distribution and temporal variation of drought in Inner Mongolia during 1901-2014 using Standardized Precipitation Evapotranspiration Index. - Science of The Total Environment 654: 850-862.

DOI: $10.1016 /$ j.scitotenv.2018.10.425.

[31] Wilhite, D. A., Glantz, M. H. (1985): Understanding: The Drought Phenomenon: The Role of Definitions. - Water International 10(3): 111-120.

DOI: $10.1080 / 02508068508686328$.

[32] Yu, M., Li, Q., Hayes, M. J., Svoboda, M. D., Heim, R. R. (2014): Are droughts becoming more frequent or severe in China based on the Standardized Precipitation Evapotranspiration Index: 1951-2010? - International Journal of Climatology 34(3): 545558. DOI: $10.1002 /$ joc.3701.

[33] Zambreski, Z. T. (2016): A Statistical Assessment of Drought Variability and Climate Prediction for Kansas. - Master of Science Thesis, Department of Agronomy, Kansas State University, Manhattan, Kansas. 
[34] Zhang, A., Jia, G. (2013): Monitoring meteorological drought in semiarid regions using multi-sensor microwave remote sensing data. - Remote Sensing of Environment 134: 1223. DOI: $10.1016 /$ j.rse.2013.02.023.

[35] Zhou, Y., Li, N., Ji, Z., Gu, X., Fan, B. (2013): Temporal and Spatial Patterns of Droughts Based on Standard Precipitation Index (SPI) in Inner Mongolia during 19812010. - Journal of Natural Resources 28(10): 1694-1706.

DOI: $10.11849 /$ zrzyxb.2013.10.005. 